EESTI NSV TEADUSTE AKADEEMIA TOIMETISED. 23. KOIDE KEEMIA * GEOLOOGIA. 1974, NR. 3

НЗВЕСТИЯ АКАДЕМИИ НАУК ЭСТОНСКОИ ССР. ТОМ 23 ХИМИЯ * ГЕОЛОГИЯ. 1974, № 3

удК $541.64 ; 543.42$

О. КИРРЕТ, Э. ЛИППМАА, Т. ПЕХК

\title{
АНАЛИЗ ПОЛИАМИДНЫХ ВОЛОКОН МЕТОДОМ ЯМР ${ }^{13} \mathrm{C}$
}

O. KIRRET, E. LIPPMAA, T. PEHK. SOSINIK-13 TMR SPEKTROSKOOPIA KASUTAMINE POLO. AMIIDSETE KIUDAINETE ANALOUSIKS

O. KIRRET, E. LIPPMAA, T. PEHK. ANALYSIS OF POLYAMIDE SYNTHETIC FIBRES BY CMR SPECTROSCOPY

Спектроскопия ЯМР высокого разрешения ядер ${ }^{13} \mathrm{C}$ должна являться удобным методом идентификации текстильных волокон с их растворов. В данной работе рассматривается возможность использования спектров ЯМР ${ }^{13} \mathrm{C}$ для идентификации синтетических полиамидных волокон.

Синтетические полиамиды достаточно хорошо растворяются в холодной муравьиной кислоте или в феноле. С этих довольно вязких растворов (около 20\% полиамида в растворителе) получаются обычные спектры ${ }^{13} \mathrm{C}$ высокого разрешения. Сравнительный анализ отдельных синтетических полиамидов проведен в муравьиной кислоте при комнатной температуре.

Спектры ЯМР ${ }^{13} \mathrm{C}$ сняты на универсальном спектрометре ['] при частоте 15,1 Мгц с применением шумовой развязки от протонов в импульсном режиме с Фурье-преобразованием и с иопользованием мини-ЭВM «Nicolet $1083 »$ для цифрового накопления и преобразования сигнала. Химические сдвиги измерены относительно пика муравьиной кислоты $\left(\delta_{\text {тмс }}=\right.$ $=166,5$ м. д.) и переведены в ТMC-шкалу. В использованных условиях спектры с отношением сигнала к шуму $>30$ могут быть зарегистрированы в течение нескольких минут. Уменьшение концентрации полиамида в муравьиной кислоте не ведет к существенному изменению химических сдвигов. Отнесение линий полиамидов базируется на анализе спектра полиамида 6 . Химический сдвиг карбонильной группы легко определяется по ее характерной величине около 178 м.д., что находится в диапазоне резонанса карбонильной группы в амидах карбоновых кислот $\left[{ }^{2}\right]$. Химический сдвиг среднего из пяти метиленовых групп (28,6 м.д.) независимо от характера концевых групп близок к химическому сдвигу средних метиленовых групп н-алканов с длинной цепью (около 29 м.д.). Из низкопольных метиленовых групп при 40,7 у 36,0 м.д. последний должен относиться к $\alpha$-метиленовому углеродному атому от карбонильной группы, так как- $\mathrm{N}$-алкиламидная группа мало влияет на химический сдвиг метильного углеродного атома в ацетамидах по сравнению с уксусной кислотой $[3,4]$, а химический сдвиг $\alpha$-метиленовой группы в капроновой кислоте равняется 34,5 м.д. [4]. Сигнал при 40,7 м.д. соответствует 
Химические сдвиги ${ }^{13} \mathrm{C}$ некоторых синтетических полиамидов *

\begin{tabular}{|c|c|c|c|c|c|c|c|c|}
\hline \multirow{3}{*}{ Полиамид } & \multirow{3}{*}{$\begin{array}{c}\text { Растворн- } \\
\text { тель }\end{array}$} & \multirow{3}{*}{$\begin{array}{c}\text { Tемпе- } \\
\text { ратура, } \\
{ }^{\circ} \mathrm{C}\end{array}$} & \multicolumn{6}{|c|}{ Химические сдвиги vглеродных атомов $\delta_{\text {тмс }}$} \\
\hline & & & \multicolumn{2}{|c|}{$\begin{array}{c}\text { у атома } \\
\text { азота }\end{array}$} & \multicolumn{2}{|c|}{$\begin{array}{l}\text { у карбониль- } \\
\text { ного атома }\end{array}$} & \multirow{2}{*}{$\begin{array}{c}\text { карбо- } \\
\text { нильная } \\
\text { группа }\end{array}$} & \multirow{2}{*}{$\begin{array}{l}\text { осталь- } \\
\text { ные }\end{array}$} \\
\hline & & & $\alpha$ & $\beta$ & $\alpha$ & $\beta$ & & \\
\hline $\begin{array}{ll}\text { Полиамид } 6 \\
\text { Полиамид } & 6 \\
\text { Полиамид } & 6,6 \\
\text { Полиамид } & 7 \\
\text { Полиамид } & 6,10 \\
\text { Полиамид } 11 \\
\text { Полиамид } 11\end{array}$ & $\begin{array}{l}\mathrm{HCOOH} \\
\mathrm{PhOH} \\
\mathrm{HCOOH} \\
\mathrm{HCOOH} \\
\mathrm{HCOOH} \\
\mathrm{HCOOH} \\
\mathrm{PhOH}\end{array}$ & $\begin{array}{r}30 \\
180 \\
30 \\
30 \\
30 \\
30 \\
180\end{array}$ & $\begin{array}{l}40,7 \\
39,6 \\
40,7 \\
40.8 \\
40,6 \\
40,4 \\
39,8\end{array}$ & $\begin{array}{l}26,4 \\
24,9 \\
26,3 \\
26,3 \\
26,2 \\
26,2 \\
25,1\end{array}$ & $\begin{array}{l}36,0 \\
35,8 \\
35,4 \\
35,8 \\
35,7 \\
35,4 \\
36,0\end{array}$ & $\begin{array}{l}25,9 \\
26,2 \\
25,3 \\
25,9 \\
25,7 \\
25,7 \\
26,2\end{array}$ & $\begin{array}{l}177,8 \\
174,8 \\
177,5 \\
177,9 \\
177,9 \\
177,5 \\
175,1\end{array}$ & $\begin{array}{l}28,6(1) \\
28,6(1) \\
28,6(1) \\
28,6 \quad(2) \\
28,6 \quad(3) \\
28,6 \quad(6) \\
28,6 \quad(6)\end{array}$ \\
\hline
\end{tabular}

* В м.д. в низкое поле от внешнего тетраметилсилана.

В скобках приведены относительные интенсивности пика (высота пика пропорциональна числу соответствующих углеродных атомов).

$\alpha$-метиленовому углеродному атому от атома азота. Отнесение остальных двух близко резонирующих метиленовых углеродных атомов базируется на сравнении спектра, снятого при $180^{\circ} \mathrm{C}$ в феноле, со спектром, снятым при комнатной температуре в муравьиной кислоте. Считая химический сдвиг средней метиленовой группы равным 28,6 м.д., можно получить характерные высокопольные сдвиги на $\alpha$ - и $\beta$-положениях к атому азота, если химический сдвиг 26,4 м.д. (при комнатной температуре) приписать к $\beta$-метиленовому углеродному атому от атома азота. Эти высокопольные сдвиги объяснимы различием протонирования амидного азота в феноле и в муравьиной кислоте. Отнесение сигналов остальных полиамидов на базе химических сдвигов полиамида 6 очевидное. В первом приближении влияние карбонильной и амидной групп не распространяется дальше $\beta$-положения от атома азота или карбонильного углеродного атома. Это определяет пределы применимости спектров ЯМР ${ }^{13} \mathrm{C}$ для идентификации высших изомерных полиамидов. Однако полиамиды 6 и 6,6, которые являются изомерными соединениями, различаются, так как в их спектрах имеются малые, но характерные и вполне измеряемые различия, основными из которых считаются разные химические сдвиги метиленовых углеродных атомов в $\alpha$ - и $\beta$-положениях к карбонильной группе и разность в химических сдвигах двух высокопольных $\beta$-метиленовых групп, равную в полиамиде $6-0,5$ м.д., а в полиамиде $6,6-1,0$ м.д.

По спектрам ЯМР ${ }^{13} \mathrm{C}$ можно легко различить полиамиды 6 и 7 , поскольку последний имеет пик двойной интенсивности при 28,6 м.д. Предел различимости полиамидов, полученных из высших $\omega$-аминокарбоновых или дикарбоновых кислот и диаминов по интеноивности линии 28,6 м.д., включает все полиамиды, которы находили практическое применение. Этот предел определяется воспроизводимостью интегрирования наиболес интенсивного пика при 28,6 м.д. и возможным различием релаксационных параметров, следовательно, и интенсивностью линий, составляющих этот пик метиленовых углеродных атомов.

Таким образом, спектры ЯМР ${ }^{13} \mathrm{C}$ являются удобным, быстрым и однозначным методом идентификации всех наиболее распространенных полиамидных смол и изготовленных из них волокон и других изделий (при этом технологические особенности получения этих смол не имеют такого значения, как при других методах анализа полиамидов (пиролизная ГЖХ, ИК-спектры)). 
Л И ТЕ Р А Т У А

1. Lippma a E., Pehk T., Past J., Eesti NSV TA Toim., Füüs.-Matem., 16, 345 (1967).

2. Levy G. C., Nelson G. L., Carbon-13 NMR for Organic Chemists, Wiley Interscience, 1972.

3. Le vy G. C., N els on G. L., J. Amer. Chem. Soc., 94, 4897 (1972).

4. Li p p ma E., P e h k T., Kemian Teollisuus, 24, 1001 (1967).

\author{
Ннститут химии \\ Академии наук Эстонской ССР \\ Поступила в редакцию \\ 1/III 1974
}

Ннститут кибернетики

Академии наук Эстонской ССР

\author{
EESTI NSV TEADUSTE AKADEEMIA TOIMETISED. 23. KOIDE \\ KEEMIA * GEOLOOGIA. 1974, NR. 3 \\ ИЗВЕСТИЯ АКАДЕМИИ НАУК ЭСТОНСКОИ ССР. ТОМ 23 \\ ХИМИЯ * ГЕОЛОГИЯ. 1974, № 3
}

удк $541.141 .8: 547.68$

ЛИа ПААЛЬМЕ, ОДетТ ПЕРЭН-РУССЕЛЬ, М. ГУБЕРГРИЦ, П. ЖАКИНЬОН

\title{
ФОТОДЕГРАДАЦИЯ НЕКОТОРЫХ МЕТИЛПРОИЗВОДНЫХ 3,4-БЕНЗПИРЕНА, РАСТВОРЕННЫХ В Н-ОКТАНЕ
}

Lia PAALME, Odette PERIN-ROUSSEL, M. GUBERGRITS, P. JACQUIGNON. MONEDE 3,4-BENSOPOREENI METOOLDERIVAATIDE FOTODEGRADATSIOON $n$-OKTAANIS

Lia PAALME, Odette PERIN-ROUSSEL, M, GOUBERGRITS, P. JACQUIGNON. PHOTODEGRADATION DES CERTAINS DERIVES METHYLES DU BENZO(3.4)PYRENE. SOLUTION EN n-OCTANE

В предыдущем сообщении [1] охарактеризована кинетика фотоинициированной деградации некоторых моно- и диметилпроизводных 3,4-бензпирена (БП), растворенных в бензоле. На последующем этапе исследования, результаты которого составляют предмет настоящей краткой публикации, аналогичный эксперимент был поставлен с тем же набором полициклических углеводородов (ПАУ) при неизменных условиях и методике проведения опытов (также в атмосфере аргона и кислорода [2]), но с использованием в качестве растворителя н-октана. Перечень производных БП, подавляющая часть которых была синтезирована в лаборатории органического синтеза Института химии природных соединений Национального центра научных исследований Франции, и их структура приведены в табл. 1.

Настоящее сообщение является первым плодом непосредственного научного сотрудничества французских и советских ученых в области изучения структуры и реакционной способности канцерогенных соединений.

Основные результаты исследования в первичной графической обработке приведены на рис. 1. Рассмотрение последнего показывает, что изменение во времени концентрации реагента происходит по линейному 